\title{
Implementation of RNA sequencing and array CGH in the diagnostic workflow of the AIEOP-BFM ALL 2017 trial on acute lymphoblastic leukemia
}

\author{
Maximilian Schieck ${ }^{1}$ (D) Jana Lentes ${ }^{1} \cdot$ Kathrin Thomay $^{1} \cdot$ Winfried Hofmann $^{1} \cdot$ Yvonne Lisa Behrens $^{1} \cdot$ \\ Maike Hagedorn ${ }^{1}$ • Juliane Ebersold ${ }^{1}$ • Colin F. Davenport ${ }^{2} \cdot$ Grazia Fazio $^{3}$ - Anja Möricke ${ }^{4} \cdot$ Swantje Buchmann $^{4}$. \\ Julia Alten ${ }^{4}$. Gunnar Cario ${ }^{4}$ Martin Schrappe ${ }^{4}$. Anke Katharina Bergmann ${ }^{1}$ - Martin Stanulla ${ }^{5}$ Doris Steinemann ${ }^{1}$. \\ Brigitte Schlegelberger $^{1} \cdot$ Giovanni Cazzaniga $^{3} \cdot$ Gudrun Göhring $^{1}$
}

Received: 28 June 2019 / Accepted: 6 February 2020 / Published online: 20 February 2020

(C) The Author(s) 2020

\begin{abstract}
Risk-adapted therapy has significantly contributed to improved survival rates in pediatric acute lymphoblastic leukemia (ALL) and reliable detection of chromosomal aberrations is mandatory for risk group stratification. This study evaluated the applicability of panel-based RNA sequencing and array CGH within the diagnostic workflow of the German study group of the international AIEOP-BFM ALL 2017 trial. In a consecutive cohort of 117 children with B cell precursor (BCP) ALL, array analysis identified twelve cases with an $I K Z F 1^{\text {plus }}$ profile of gene deletions and one case of masked hypodiploidy. Genetic markers $B C R-A B L 1 \quad(n=1)$, ETV6-RUNX1 $(n=25)$, and rearrangements involving KMT2A $(n=3)$ or TCF3 $(\mathrm{n}=3)$ were assessed by established conventional techniques such as karyotyping, FISH, and RT-PCR. Comparison of these results with RNA sequencing analysis revealed overall consistency in $n=115 / 117$ cases, albeit with one undetected $A F F 1-K M T 2 A$ fusion in RNA sequencing and one undetected ETV6-RUNX1 fusion in conventional analyses. The combined application of RNA sequencing, FISH, and CGH+SNP array reliably detected all genetic markers necessary for risk stratification and will be used as the diagnostic standard workflow for BCP-ALL patients enrolled in the AIEOP-BFM ALL 2017 study. Prospectively, consistent collection of genome-wide CGH+SNP array as well as RNA sequencing data will be a valuable source to elucidate new prognostic lesions beyond established markers of pediatric ALL. In this respect, RNA sequencing identified various gene fusions in up to half of the $I K Z F I^{\text {plus }}(n=6 / 12)$ and B-other $(n=19 / 36)$ cases but not in cases with hyperdiploid karyotypes $(n=35)$. Among these fusions, this study reports several previously undescribed in frame PAX5 fusions, including $P A X 5-M Y O 1 G$ and PAX5-NCOA6.
\end{abstract}

Keywords Acute lymphoblastic leukemia $\cdot$ Fusion transcript $\cdot$ Diagnostics $\cdot$ IKZF1plus $\cdot$ Risk stratification $\cdot$ RNA sequencing

Maximilian Schieck, Jana Lentes and Kathrin Thomay contributed equally to this work.

Electronic supplementary material The online version of this article (https://doi.org/10.1007/s00277-020-03953-3) contains supplementary material, which is available to authorized users.

Maximilian Schieck

schieck.maximilian@mh-hannover.de

1 Department of Human Genetics, Hannover Medical School, Carl-Neuberg-Str. 1, 30625 Hannover, Germany

2 Research Core Unit Genomics, Hannover Medical School, Hannover, Germany
3 Centro Ricerca Tettamanti, Pediatric Clinic, University of Milano-Bicocca, Fondazione MBBM, Monza, Italy

4 Department of Pediatrics, University Hospital Schleswig-Holstein, Campus Kiel, Kiel, Germany

5 Pediatric Hematology and Oncology, Hannover Medical School, Hannover, Germany 


\section{Abbreviations}

ALL Acute lymphoblastic leukemia

AIEOP- International collaborative treatment protocol

BFM ALL for children and adolescents with acute lymphoblastic leukemia

array CGH Array-based comparative genomic hybridization

B-I B-lineage immunophenotype pro-B-ALL

B-II B-lineage immunophenotype common-ALL

B-III B-lineage immunophenotype pre-B-ALL

BCP-ALL B cell precursor acute lymphoblastic leukemia

BM Bone marrow

B-other Subtype of cases that tested negative for genetic markers relevant for AIEOP-BFM ALL 2017

CDS Coding sequence

FISH Fluorescence in situ hybridization

$I K Z F 1^{\text {plus }} \quad$ Profile of gene deletions relevant for risk stratification within AIEOP-BFM ALL 2017

ISCN International System for Human Cytogenetic Nomenclature

MRD Minimal residual disease

RNA-seq RNA sequencing

RT-PCR Reverse transcriptase polymerase chain reaction

\section{Introduction}

Acute lymphoblastic leukemia (ALL) is the most frequent childhood malignancy with an assumed worldwide annual incidence of more than 50,000 cases [1,2]. Fortunately, many clinical trials recently demonstrated 5-year survival rates above $90 \%$ in pediatric ALL, whereas only a few decades ago, survival rates were below $20 \%[1,3]$. The great improvement in prognosis is essentially a result of iterative cycles of long-term clinical trials. These trials helped to identify biologic subtypes of ALL, to assess their distinct response to treatment and risk of relapse, and to develop individual riskadapted therapies [4].

Risk stratification within the recently completed AIEOP-BFM ALL 2009 trial, an international collaborative treatment protocol for children and adolescents with acute lymphoblastic leukemia, was based on immunophenotype, specific chromosomal aberrations, and response to treatment assessed by minimal residual disease (MRD). The two chief chromosomal aberrations relevant to risk stratification in AIEOP-BFM ALL 2009 were the AFF1-KMT2A gene fusion and a hypodiploid karyotype. The fusion $B C R-A B L 1$ represented an exclusion criterion and those cases were treated within the EsPhALL study [5]. Cases showing none of these genetic markers were treated based on their response to treatment and MRD has proven to be an effective measure to identify patients with a high risk of relapse [6]. However, it is known that other genetic aberrations, some of them recurrent, exist in the MRD high-risk group and great efforts are being made to identify and characterize these aberrations, as this knowledge will be key to improve risk stratification, to introduce targeted treatment, and hopefully to increase long-term survival rates [7]. Therefore, the diagnostic workflow of the current AIEOP-BFM ALL 2017 study investigates for an extended set of stratification relevant gene fusions (i.e., ETV6-RUNX1, AFF1$K M T 2 A$, and $T C F 3-H L F)$ as well as the $I K Z F 1^{\text {plus }}$ subtype $[8,9]$. It is noteworthy that $I K Z F 1^{\text {plus }}$ is not defined by a single genetic aberration, but by deletions in six different genetic loci (i.e., deletion of IKZFI complemented by at least one additional deletion in $C D K N 2 A, C D K N 2 B$, $P A X 5$, or CRLF2-P2RY8, and no deletion in ERG) [8]. The $I K Z F 1^{\text {plus }}$ profile of gene deletions points at the necessity that future routine diagnostic workflows, which are currently often limited to specific genes of interest using fluorescence in situ hybridization (FISH) and polymerase chain reaction (PCR) analyses, will have to assess a wider range of targets in order to detect novel and yet undefined profiles relevant to risk stratification.

We here report on our results from implementing analysis of the leukemia transcriptome using panel-based RNA sequencing and genome-wide copy-number analysis using array CGH into the diagnostic workflow of the German study group of the international AIEOP-BFM ALL 2017 trial. In addition to assessing detection of $I K Z F 1^{\text {plus }}$ in array $\mathrm{CGH}$, the major aim of this study was to compare the RNA-seq-based detection of above mentioned gene fusions with well-established techniques such as karyotyping, FISH, and PCR analyses. We also discuss expanded use of RNA-seq data beyond stratification relevant gene fusions, which in some cases identified potentially targetable lesions. Prospectively, the consistent collection of genome-wide CGH+SNP array as well as RNA-seq data within the AIEOP-BFM ALL 2017 trial is a valuable resource for elucidation of new prognostic markers of pediatric ALL.

\section{Methods}

\section{Patients and samples}

This study was performed on a consecutive cohort of patients with pediatric ALL sent to our genetic reference laboratory for initial cytogenetic and molecular genetic diagnostics. All patients were treated in German centers and were enrolled in the AIEOP-BFM ALL 2009 trial (EudraCT no. 2007-00427043). Written informed consent was obtained from the legal representatives (and the patients, if applicable). The study cohort consisted of $n=117$ patients ( $n=65$ male, $n=52$ female) with a median age of 4.8 years. Of these patients, $6(5.1 \%)$ were classified with an immunophenotype of pro-B-ALL (B- 
I), $72(61.5 \%)$ with a common-ALL (B-II), and 39 (33.3\%) with a pre-B-ALL (B-III).

Bone marrow (BM) aspirate was obtained at the time of initial diagnosis. BM from heparinized tubes was used for cytogenetic analyses (karyotyping and FISH). RNA was preferably isolated from EDTA BM, or if necessary from heparin $\mathrm{BM}$, on a Chemagic 360 instrument as per the manufacturer's instructions (PerkinElmer, Baesweiler, Germany). RNA integrity (RIN value) was measured by Bioanalyzer 2100 (Agilent Technologies, Waldbronn, Germany). Isolation of DNA from EDTA BM was performed using the QIAamp DNA Blood Midi Kit (Qiagen, Hilden, Germany).

\section{Genetic markers relevant for risk stratification}

This study assisted to optimize the diagnostic standard workflow of the German study group of the AIEOP-BFM ALL 2017 trial. Using the methods listed below, the following genetic markers relevant for risk stratification were evaluated: gene fusions (ETV6-RUNX1, AFF1-KMT2A, and TCF3$H L F$ ), hypodiploidy ( $<45 \mathrm{chr}$ ), and $I K Z F 1^{\text {plus }} . B C R-A B L 1$ is an exclusion criterion for the AIEOP-BFM ALL trial, as these cases are treated within the EsPhALL study instead.

\section{Karyotyping and FISH analysis}

For all patients, short-term cultures (24-48 h) were set up from BM aspirates. Chromosome preparation, fluorescence Rbanding, and FISH were performed as previously described [10]. Karyotypes were described according to the International System for Human Cytogenetic Nomenclature (ISCN, 2016). In addition to classical banding analysis, the diagnostic standard protocol included FISH analyses for $B C R$ $A B L 1$ and ETV6-RUNX1 fusions as well as for translocations affecting the genes KMT2A and TCF3 (FISH probes: Vysis LSI $B C R / A B L$ Dual Color, Abbott, Wiesbaden, Germany; Vysis LSI ETV6(TEL)/RUNX1(AML1) ES Dual Color, Abbott; Vysis LSI MLL(KMT2A) Dual Color, Abbott; SureFISH 19p13.3 TCF3 DF, Agilent) [10].

\section{Reverse transcriptase PCR}

Reverse transcriptase PCR (RT-PCR) was performed in parallel to cytogenetic analyses whenever EDTA-material was available (74/117 cases) for the qualitative detection of fusion transcripts of BCR-ABL1, ETV6-RUNX1, and AFF1-KMT2A as published elsewhere $[11,12]$. In cases where only heparinized material was available, no RT-PCR was performed due to possible inhibitory effects of heparin on amplification. cDNA quality was verified by quantification of the $A B L 1$ gene.

\section{Panel-based RNA sequencing and data analysis}

RNA-seq was performed using the TruSight RNA Pan-Cancer Panel (Illumina, San Diego, CA, USA) according to the manufacturer's instruction. The panel targets 1385 cancer genes (see online Tab.S1) and detects fusions between genes targeted by the panel but also fusions of targeted genes with non-target genes. Prior to this study, the RNA-seq method was successfully validated on commercially available reference material (SeraSeq ${ }^{\circledR}$ Myeloid Fusion RNA Mix, Hiss Diagnostics GmbH, Freiburg, Germany), external reference samples with defined fusions provided by the group of Giovanni Cazzaniga (University of Milano-Bicocca, Fondazione MBBM, Monza, Italy), and genetically characterized cell lines and samples from our laboratory (see Tab.S2 for tested fusions). Gene-pseudogene "fusions" and recurrent technical artifacts were defined during this validation process and excluded from later data analysis. Each RNA-seq run contained a pooled cDNA library of eight patient samples and was executed on an Illumina MiSeq machine using MiSeq ${ }^{\circledR}$ Reagent Kit v3 (150 cycles) with a PE MiSeq ${ }^{\circledR}$ Flow Cell. The anticipated minimum number of reads per sample was 3 million.

Data analysis was performed using the Illumina BaseSpace apps TopHat Alignment (version 1.0.0, read mapping on hg19 reference genome by TopHat2 [13], fusion calling by TopHatFusion [14]) and RNA-seq Alignment (version 1.1.0, read mapping on hg19 reference genome by STAR [15], fusion calling by Manta [16]) using standard settings (https:// basespace.illumina.com/apps). Fusion transcripts with a low number of split-reads $(<10)$ were excluded as likely falsepositives, unless the fusion was verified with a second method. The turn-around time from RNA isolation to detection of fusion transcripts using this workflow is 4 days.

Validation of single gene fusions detected in RNA-seq was carried out using the HemaVision®-28N multiplex RT-PCR Kit if applicable and according to the manufacturer's instructions (DNA Diagnostic, Risskov, Denmark).

\section{Array CGH}

Array-based comparative genomic hybridization (array CGH) was performed using a $400 \mathrm{k}$ SurePrint G3 Custom CGH Human Genome Microarray (e-Array design 84704, Agilent Technologies, Waldbronn, Germany) according to the manufacturer's protocol by hybridizing $500 \mathrm{ng}$ of patient DNA isolated from EDTA material against sex-matched human reference DNA (Megapool Reference DNA, Kreatech, Amsterdam, The Netherlands). Regions of genomic copy number change were analyzed and interpreted with Agilent Genomic Workbench 7.0 software under the following analysis setting: aberration detection algorithm ADM-2, threshold 6.0, aberration filter of at least four aberrant probes (resulting 
in an average genome-wide resolution of $\sim 30 \mathrm{~kb}$ ), and average $\log 2$ ratios of +0.3 for gains and -0.3 for losses.

The original description of the $I K Z F 1^{\text {plus }}$ gene deletion profile by Stanulla et al. has been based on MLPA analyses targeting IKZF1, CDKN2A, CDKN2B, PAX5, and CRLF2$P 2 R Y 8$, as well as multiplex PCR for the detection of $E R G$ deletions. Prior to this study, reproducibility of $I K Z F 1^{\text {plus }}$ profiles in our high-resolution array $\mathrm{CGH}$ was verified for selected cases (data not shown).

Cases indicative of masked hypodiploidy (i.e., presence of multiple tetrasomies) were analyzed on CGH+SNP array (eArray design 85320, Agilent Technologies) using sexmatched reference DNA (Human Reference DNA, Agilent Technologies).

\section{Results}

\section{Panel-based RNA-seq results are consistent with fusions detected by cytogenetic and RT-PCR analyses}

Within the cohort of 117 consecutive patients with pediatric BCP-ALL, the following genetic markers relevant for inclusion/exclusion and risk stratification of patients were observed: $B C R-A B L 1$ fusion ( $n=1$; exclusion criterion and referral to EsPhALL trial), ETV6-RUNX1 fusion $(n=26)$, $A F F 1-K M T 2 A$ fusion $(n=2)$, hypodiploidy $(n=1)$, and $I K Z F I^{\text {plus }}(n=12)$. Other observed genetic markers not relevant for risk stratification within the AIEOP-BFM ALL 2017 trial were as follows: $T C F 3$ rearrangement $(n=3$; $T C F 3$ $P B X 1$ fusions), KMT2A rearrangement ( $n=1 ; K M T 2 A-$ $M L L T 1$ fusion; aberration is only relevant for stratification in cases $<1$ year of age), and hyperdiploid karyotype with more than 50 chromosomes $(n=35)$. The remaining $n=36$ cases were classified as B-other due to absence of the abovementioned genetic markers (Table 1).

Fusion detection by RNA-seq was highly consistent with results obtained from cytogenetic and RT-PCR analyses for 115 out of 117 analyzed cases. The two discordant cases were case 29, which was misclassified by RNA-seq, and case 26, which was misclassified in conventional analyses (see online Tab.S3 for a complete overview on all cases and results). In detail, case 29 presented in FISH analysis with a split of the KMT2A locus and subsequent analyses using FISH on interphase and metaphase nuclei as well as RT-PCR using the HemaVision-28N kit were able to identify this fusion to be derived from a small insertion of the $5^{\prime} K M T 2 A$-Locus into chromosome 4 (ins(4;11)). However, this cryptic $A F F 1$ $K M T 2 A$ fusion was not reported by either of the two Illumina BaseSpace apps, despite its existence in the raw RNA-seq reads. The dependency on accurate fusion calls by alignment algorithms was also indicated by other cases in this study. Case 15 tested positive for ETV6-RUNX1 fusion in FISH and RT-PCR analyses, whereas only the RNA-seq Alignment app and not the TopHat Alignment app detected this fusion. In contrast, all nine cases with $P 2 R Y 8-C R L F 2$ fusions were detected by the TopHat Alignment app only (cases 55-63).

On the other side, conventional analyses also generated one false negative result in this study. FISH and regular RT-PCR indicated no ETV6-RUNX1 fusion for case 26, whereas RNAseq gave a positive result. Subsequently, the fusion of ETV6RUNX1 could be confirmed using the HemaVision-28N multiplex RT-PCR Kit. In detail, analysis of the RNA sequence revealed a fusion of ETV6 exon 5 to RUNX1 exon 3, which should have been detectable by routine RT-PCR primers and FISH analyses. Furthermore, case 16 showed an ETV6RUNX1 fusion in RNA-Seq and FISH resulting from a variant breakpoint in ETV6 exon 4, which could not be detected via routine RT-PCR due to a loss of the primer binding site.

All other fusions addressed by karyogram, FISH, or RTPCR were either confirmed (i.e., BCR-ABL1, PBX1-TCF3) or specified in more detail by RNA-seq, as was the case for the identification of MLLT1 as the fusion partner of KMT2A (11q23.3-19p13.3; case 30).

\section{Array CGH identifies $I K Z F 7^{\text {plus }}$ cases in B-other and hyperdiploid subtypes of BCP-ALL}

All cases negative for a risk stratifying marker in cytogenetic and RT-PCR analyses were analyzed by array CGH for presence of the $I K Z F 1^{\text {plus }}$ deletion profile. Under these conditions, a total of 84 cases qualified for array CGH (two of these cases had insufficient DNA from time point of diagnosis). The $I K Z F 1^{\text {plus }}$ deletion profile was observed in twelve cases. With a median age of 8.7 compared with 4.8 years, the $I K Z F 1^{\text {plus }}$ cases were older than the overall cohort (Table 1). In all cases, the mandatory deletion of IKZF1 was accompanied by chromosome 9 deletions, whereas no interstitial deletions between $P 2 R Y 8$ and $C R L F 2$ were observed (Table 2). The gene $I K Z F 1$ was affected by small intragenic deletions, except for cases 33, 35, and 43. Various deletions could be observed on chromosome 9, ranging from small focal deletions up to losses of the entire chromosomal arm. At the conclusion of induction therapy, nine cases had a positive MRD result and would therefore qualify for the high-risk treatment group of the AIEOP-BFM ALL 2017 trial (Table 2).

\section{RNA-seq detects gene fusions in the $I K Z F 1^{\text {plus }}$ and B-other subtypes but not in hyperdiploid BCP-ALL}

As expected, RNA-seq also identified fusions between genes not covered by the diagnostic standard protocol of the AIEOPBFM ALL 2017 trial. No fusions were detected in the large group of hyperdiploid cases, while fusion transcripts were 
Table 1 Characteristics of the cohort of 117 consecutive cases with pediatric BCP-ALL. Patients were enrolled to the AIEOP-BFM ALL 2009 trial at different participating clinics throughout Germany. The sex and age distribution of the total cohort was within the expected range of pediatric BCP-ALL $[17,18]$. Genetic markers relevant for inclusion/ exclusion of patients and risk stratification within the AIEOP-BFM ALL 2017 trial are listed in the upper part of the table. Array CGH identified the $I K Z F 1^{\text {plus }}$ gene deletion profile in twelve cases $(10 \%)$ and
$\mathrm{CGH}+\mathrm{SNP}$ array identified one case of masked hypodiploidy. Beyond ETV6-RUNX1, BCR-ABL1, AFF1-KMT2A, and TCF3-PBX1 fusions, RNA-seq identified additional fusion transcripts in half of $I K Z F 1^{\text {plus }}$ cases and in about half of B-other cases (details in Table 3). Furthermore, one case with a KMT2A split signal in FISH analysis could be specified as a KMT2A-MLLT1 fusion by RNA-seq. na, not applicable due to small number of cases

\begin{tabular}{|c|c|c|c|c|}
\hline & Genetic subtype & Number of cases & Ratio male/female & Median age years (min-max) \\
\hline \multirow[t]{7}{*}{ Relevant for risk stratification } & $B C R-A B L 1$ & $1(1 \%)$ & na & na \\
\hline & ETV6-RUNX1 & $26(22 \%)$ & 1.36 & $4.0(1.6-17.9)$ \\
\hline & $A F F 1-K M T 2 A$ & $2(2 \%)$ & na & na \\
\hline & Hypodiploidy & $1(1 \%)$ & na & na \\
\hline & $I K Z F 1^{\text {plus }}$ & $12(10 \%)$ & 2.00 & $8.7(2.5-17.0)$ \\
\hline & $I K Z F 1^{\text {plus }}$ with fusion in RNA-seq & $6(5 \%)$ & 2.00 & $8.6(2.5-17.0)$ \\
\hline & $I K Z F 1^{\text {plus }}$ without fusion in RNA-seq & $6(5 \%)$ & 2.00 & $8.7(3.6-15.2)$ \\
\hline \multirow[t]{7}{*}{ Not relevant for risk stratification } & $T C F 3$ rearrangement & $3(3 \%)$ & na & na \\
\hline & $K M T 2 A$ rearrangement & $1(1 \%)$ & na & na \\
\hline & B-other & $36(31 \%)$ & 1.00 & $6.2(1.2-17.4)$ \\
\hline & B-other with fusion in RNA-seq & $17(15 \%)$ & 0.70 & $4.2(2.2-15.0)$ \\
\hline & B-other without fusion in RNA-seq & $19(16 \%)$ & 1.38 & $9.5(1.2-17.4)$ \\
\hline & Hyperdiploidy (>50 chr.) & $35(30 \%)$ & 1.19 & $4.2(2.1-13.8)$ \\
\hline & Total & 117 & 1.25 & $4.8(0.3-17.9)$ \\
\hline
\end{tabular}

detected at a high frequency in up to half of the cases in subtypes $I K Z F 1^{\text {plus }}(n=6 / 12$ cases $)$ and B-other $(n=17 / 36$ cases, Table 1 ). Of these 23 cases, only 13 presented an aberrant karyotype in banding analysis (online Tab.S3).

Cases with an aberrant karyotype displayed the following fusions: ETV6-NTRK3 (12p13.2-15q25.3), PAX5-NCOA6 (9p13.2-20q11.22), TERF2-JAK2 (16q22.1-9p24.1), HOOK3-FGFR1 (8p11.21-8p11.23), MEF2D-BCL9 (1q221q21.2), PAX5-DACH1 (9p13.2-13q21.33), PAX5-ETV6 (9p13.2-12p13.2), PAX5-LINC01251 (9p13.2-9p13.3), ZNF618-NUTM1 (9q32-15q14), and P2RY8-CRLF2 $(n=5$ cases, Xp22.33 and Yp11.2). Notably, all six cases with a structurally aberrant chromosome $9 \mathrm{p}$ showed a gene fusion involving the genes JAK2 $(n=1)$ or PAX5 $(n=5)$. Fusion transcripts found in patients with a completely normal karyotype and no other markers were EBF1-PDGFRB (5q33.35q32, case 32), PAX5-MYO1G (9p13.2-7p13, case 35), and P2RY8-CRLF2 (cases 59 and 62). Fusions of ETV6-IKZF1 (12p13.2-7p12.2) and P2RY8-CRLF2 were found in two cases with normal karyotypes at a reduced level of validity (due to poor morphology and limited number of metaphases; cases 33 and 57). No metaphases were available for case 47 (fusions ETV6-IKZF1 and IKZF1-DLG2 (7p12.2-11q14.1)), case 48 (EP300-ZNF384 (22q13.2-12p13.31) fusion), and cases 56 and 60 (both $P 2 R Y 8-C R L F 2$ fusion). Presence of all fusions, except for TERF2-JAK2, IKZF1-DLG2, and HOOK3$F G F R 1$, could be indirectly confirmed by detection of an array $\mathrm{CGH}$ aberration in at least one of the two fusion genes (i.e., intronic breakpoint corresponding to the RNA-seq spanning read, Table 3). Further validation of RNA-seq fusions, including TERF2-JAK2 and HOOK3-FGFR1, was achieved by FISH results (i.e., split signal involving the corresponding gene loci), and in most cases in banding analysis (i.e., identification of respective chromosome translocations, or at least of respective aberrant chromosomes, online Tab.S3).

\section{Discussion}

This study aimed to evaluate the applicability of panel-based RNA-seq and array $\mathrm{CGH}$ for detecting relevant gene fusions as well as chromosomal deletions for risk stratification of pediatric BCP-ALL patients. This knowledge is intended to support optimization of the diagnostic workflow of the German study group of the international AIEOP-BFM ALL 2017 trial by reducing the number of necessary diagnostic tests, while assuring robustness of aberration detection. As discussed later, the here presented results conclusively show that panel-based RNA-seq and CGH+SNP array are powerful tools for the detection of fusion genes and genome-wide copy number aberrations. However, these techniques still need to be supported by FISH analysis in order to guarantee reliable detection of relevant fusions for all cases. The second and more broadly defined aim of this study was to examine the detection of genetic lesions beyond established markers, as recent publications have demonstrated that patients of the B-other subtype 


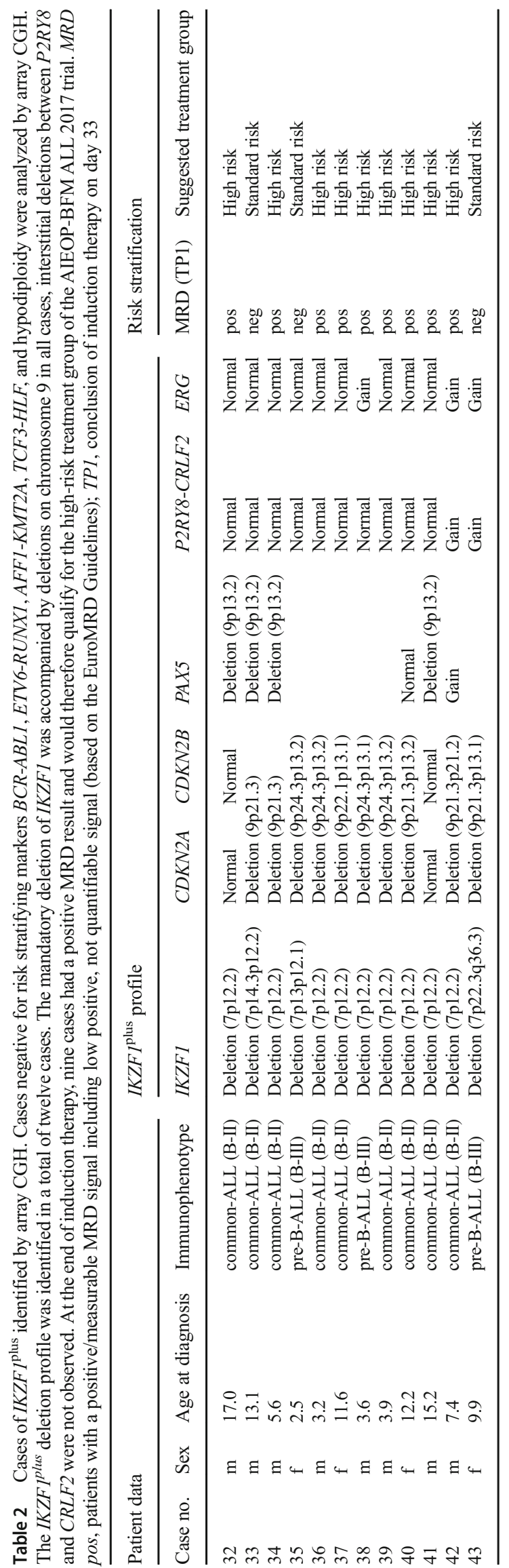

frequently harbor fusion transcripts of possible therapeutic relevance [19-21]. Prospectively, successful integration of genome-wide CGH+SNP array and RNA-seq targeting almost 1385 transcripts into the AIEOP-BFM ALL 2017 diagnostic workflow could help to generate the data essential for revealing new genetic markers of pediatric ALL in the future.

The $I K Z F 1^{\text {plus }}$ subtype itself is a good example for a new risk marker, which has been identified due to simultaneous consideration of multiple genetic loci. Notably, without analysis for $I K Z F 1^{\text {plus }}$, ten cases of this study would have been assigned as B-other and two cases as hyperdiploid ALL, with no further genetic risk stratification in both groups. One needs to be aware that occasional $I K Z F I^{\text {plus }}$ profiles might be present in cases not tested by array CGH in our workflow (e.g., ETV6-RUNX1). Projected onto the whole cohort of 117 BCP-ALLs, we therefore observed $I K Z F 1^{\text {plus }}$ in at least $10 \%$ of the cases, which is higher than the originally published share of $6 \%$ by Stanulla et al. [8]. Use of array CGH instead of MLPA and PCR-based analysis does not seem to be the reason for this discrepancy, as all deletions relevant for of $\left.I K Z F\right|^{\text {plus }}$ (Tab.S4) would be detectable by MLPA analyses as described by Stanulla et al. Furthermore, the $E R G$ locus is covered by 37 array CGH probes, of which seven probes are located in the region assessed by $E R G$ deletion PCR in Stanulla et al. Despite the satisfactory probe coverage of $E R G$ in array CGH, the higher sensitivity of PCR for deletion detection needs to be acknowledged, which might influence $I K Z F 1^{\text {plus }}$ detection. However, the high number of $I K Z F I^{\text {plus }}$ cases in our study is more likely to be explained by the small cohort size in our analysis as our extended array CGH data set on more than 600 cases comprises a lower number of $I K Z F 1^{\text {plus }}$ within the Bother and hyperdiploid cases (data not shown). In line with Stanulla et al., the age of onset of $I K Z F 1^{\text {plus }}$ cases was considerably higher than observed in the complete cohort (median age 8.7 vs 4.8 years, Table 1). It is important to mention that in the AIEOP-BFM ALL 2017 trial, the final risk stratification within $I K Z F 1^{\text {plus }}$ is dependent on MRD-levels and not all cases with an $I K Z F 1^{\text {plus }}$ deletion profile receive high-risk treatment. Within our cohort, nine of the twelve $I K Z F I^{\text {plus }}$ cases were MRD positive or inconclusive on treatment day 33 and therefore would be assigned to the high-risk treatment group of the AIEOP-BFM ALL 2017 trial.

In summary, array CGH analysis is a well-established method in many laboratories and in our study, its implementation in the diagnostic workflow was successful without difficulty. One important limitation of the method is the amount of leukemic blasts in BM aspirate obtained at the time of diagnosis, which should be at least $20 \%$ in order to reliably detect leukemia-associated genetic aberrations. On the other hand, $\mathrm{CGH}+\mathrm{SNP}$ array proved to be more sensitive in detecting hyperdiploidy, which is in line with the previous observation that hyperdiploid leukemic cells frequently fail to proliferate in culture, thus resulting in an absence of aneuploidy in analyzed metaphases or deficiency of metaphases in general (Tab.S3 cases 83, 85, 90, 91, 94, 116) 
응.

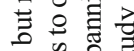

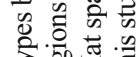

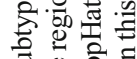

ज

융 00 응

向:

空 0 .

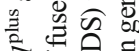

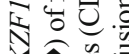

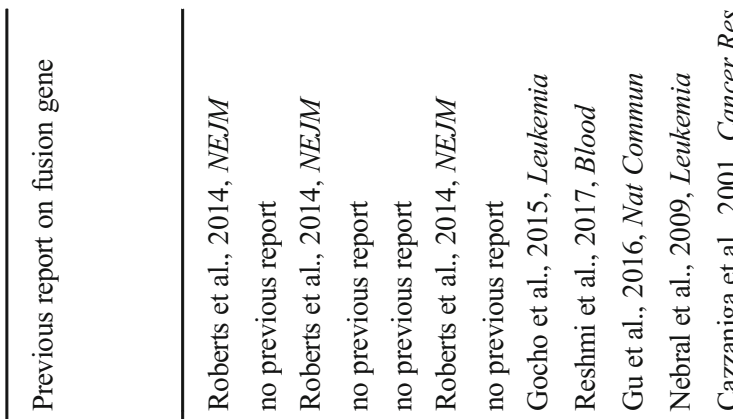
$\approx$

$\leq \uparrow$ 过

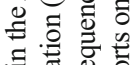

㱐敢

응

के के

in i⿱

年

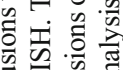

柁

品.

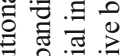

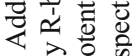

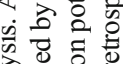

要

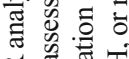

论

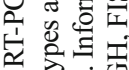

ᄒ 흉

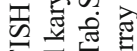

कo क ज

들 을

ठ룽

政

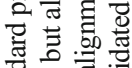

焉表覀

s ह 융

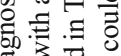

要

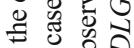

조읭ㅇㅇ

焉 焉

它造.

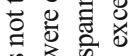

की

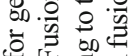

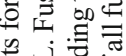

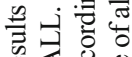

包造

可焅

远语咅

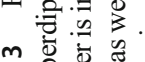

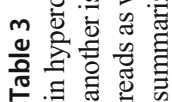

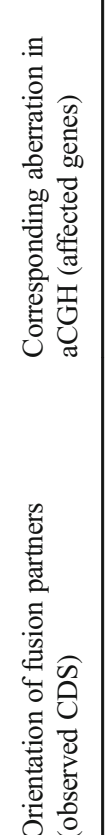

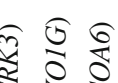

in

च च च च

不

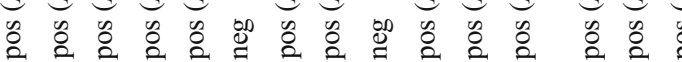

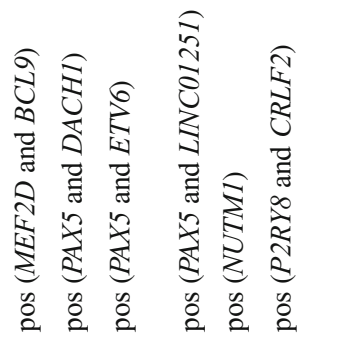

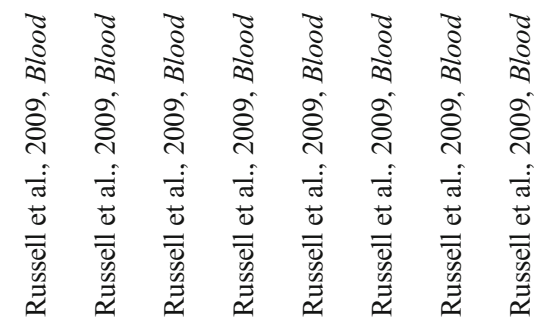
(1)

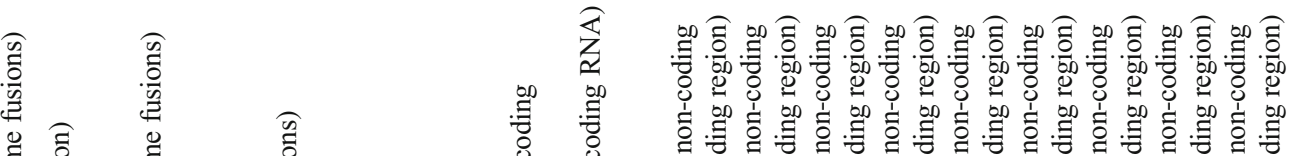

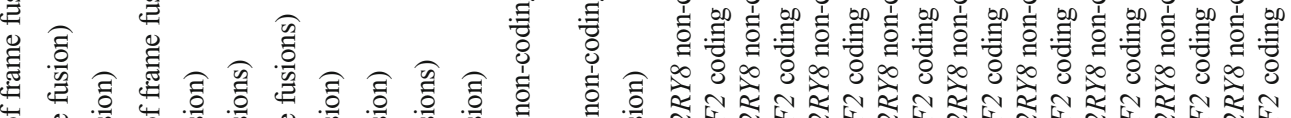

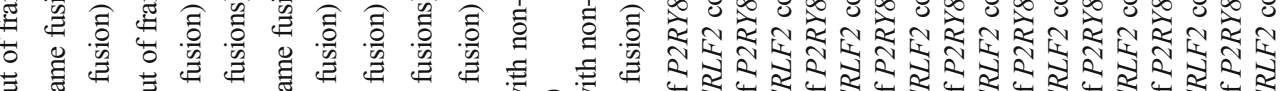

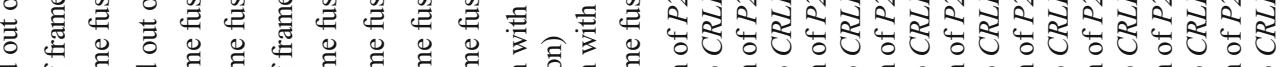

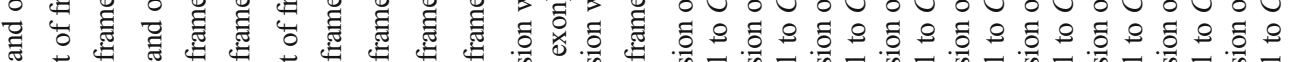

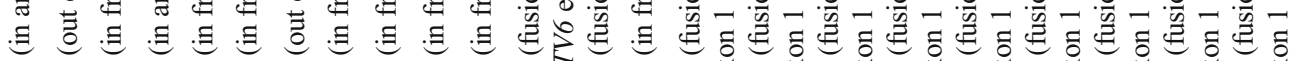

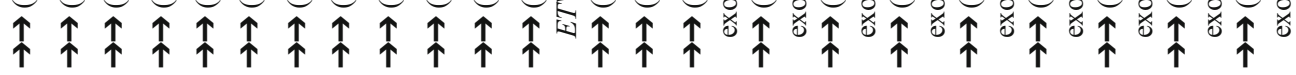

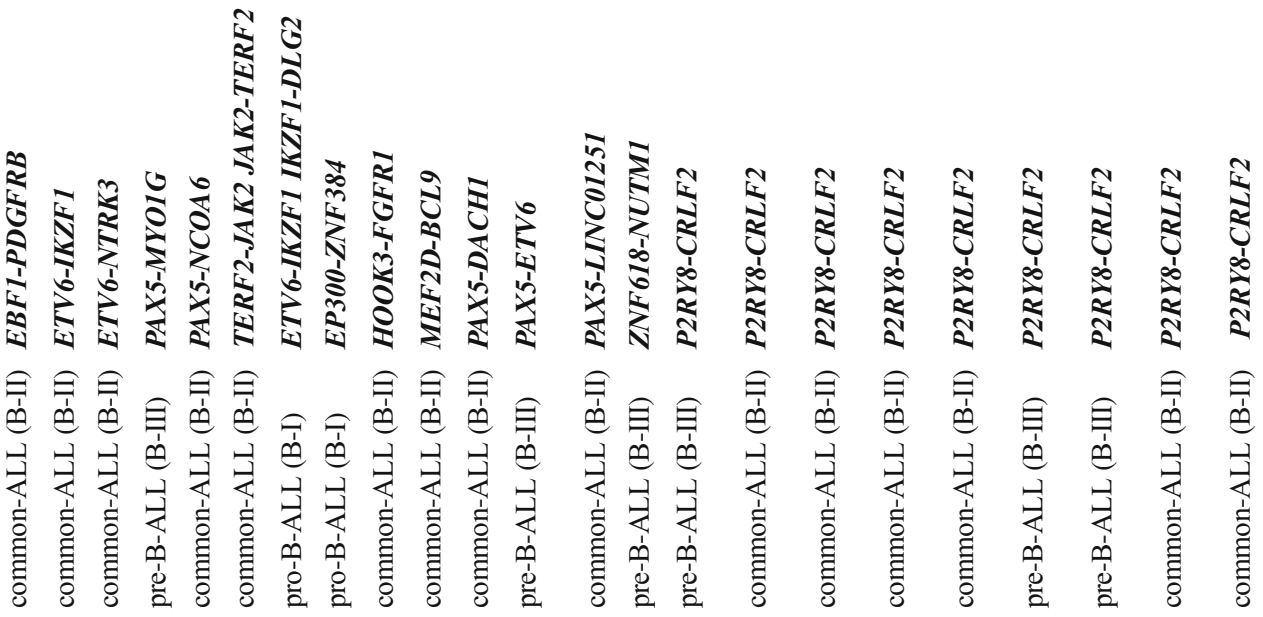

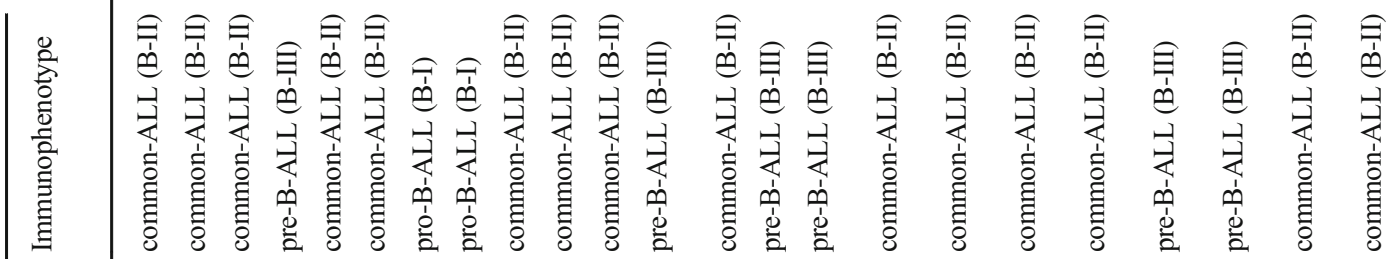

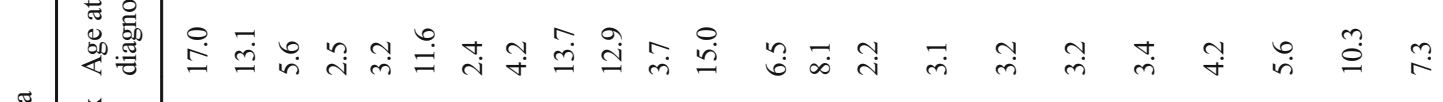

焉

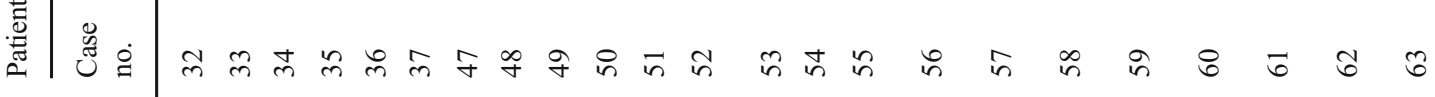

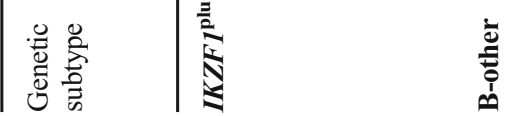


[22]. Furthermore, array analysis identified other highly relevant genetic aberrations beyond $I K Z F I^{\text {plus }}$, e.g., masked hypodiploidy and aberrations in line with fusions observed in RNA-seq analysis. For these reasons, copy number analysis using CGH+SNP arrays will be a central diagnostic tool in the AIEOP-BFM ALL 2017 trial to detect the current stratification relevant markers as well as to generate high-resolution genome-wide data for the definition of future genetic markers.

Detection of fusion genes using RNA-seq is a comparably new approach and not yet established in routine diagnostics for most malignancies. Our data demonstrate consistent results between RNA-seq and our routine diagnostic methods (karyogram, FISH, and RT PCR analyses). Considering the stratification relevant aberrations BCR-ABL1 and ETV6-RUNX1 as well as rearrangements involving either $K M T 2 A$ or $T C F 3$, which are relevant for stratification if resulting in an AFF1-KMT2A or TCF3$H L F$ fusion, only two discrepant results were observed (cases 26 and 29). For case 26, RNA-seq outperformed the routine FISH and RT-PCR methods by identifying an ETV6-RUNX1 fusion, which could later be confirmed with a second RT-PCR kit. The reason for the failure of the routine methods to detect this fusion is still unclear. Case 29, with a small insertion of $K M T 2 A$ into the $A F F 1$ gene, was the only example of a clear failure in fusion detection by RNA-seq. Even though present as multiple, identical reads at the RNA-seq raw data level, both applied alignment algorithms did not report the $A F F 1-K M T 2 A$ fusion, as they require the presence of at least three non-identical split reads for fusion calling. In our study, these two discrepant cases are the only two examples for false negative results. However, further influences exist, which can cause relevant fusions to remain undetected. These include a low percentage of leukemic blasts, loss of blasts during cell culture, cryptic or variant translocations, poor RNA quality, and notably the sensitivity of bioinformatics algorithms. Importantly, not all methods (karyogram, FISH, RT-PCR, and RNA-seq) are equally affected by these influences and a combination of methods would be able to rectify their respective weaknesses in most cases. Therefore, the diagnostic workflow of the German study group of AIEOP-BFM ALL 2017 trial will use FISH and panel-based RNA-seq as standard techniques for the detection of fusion genes. Karyotyping and RT-PCR will still be available but restricted to inconclusive cases only.

As a technical prerequisite, both alignment tools tested in this study will be applied in future RNA-seq analyses, as some fusions, like P2RY8-CRLF2, were detected by one of the algorithms only. Furthermore, the minimum number of sequencing reads per sample will be set to 3 million reads, even though our current data indicate that some fusion transcripts, like ETV6RUNX1, are detectable at coverages below 2 million reads. However, a higher number of reads per sample will also facilitate detection of lowly expressed fusion genes as well as detection of fusions in samples with low blast counts. We detected no correlation between RNA-seq coverage and RIN value or $A B L 1$ copy numbers in RT-PCR analysis (data not shown). Thus, variance in
RNA-seq coverage in our study might rather be a result of differences in library preparation and quantification, which can possibly be addressed by standardization and automatization of RNA-seq protocols. Another important technical aspect of our study is that RNA-seq was conducted on RNA isolated from BM in EDTA tubes sent to our laboratory within $24 \mathrm{~h}$. Our results indicate that use of RNA stabilizing solutions, at least for the fusion genes of interest, seems expendable.

It needs to be acknowledged that this workflow, despite panelbased RNA-seq and genome-wide array CGH, will not detect all aberrations present in the here defined B-other group. For example, fusions affecting the $I G H$ locus as well as translocations resulting in promoter or enhancer rearrangements (e.g., translocations of the $M Y C$ or $M E C O M$ locus) cannot be detected and these aberrations are being followed up on by FISH analysis on a research basis for selected cases. On the same note and in line with previous reports, our RNA-seq analysis detected additional fusion transcripts only in the B-other subtype, including cases $32-37$, which all would have been deemed B-other until recently if not stratified as $I K Z F 1^{\text {plus }}$ in our study [20, 21]. Interestingly, the previously described "targetable" kinase fusions $E B F 1$ PDGFRB, ETV6-NTRK3, and TERF2-JAK2 were all observed within the $I K Z F 1^{\text {plus }}$ subtype $[19,23,24]$. Other detected fusions may provide prognostic information (P2RY8-CRLF2, MEF2D$B C L 9$ ) [25-27]. Many fusion transcripts have already been described in pediatric ALL (e.g., HOOK3-FGFR1, PAX5-DACH1, EP300-ZNF384, PAX5-ETV6, or ZNF618-NUTM1), even though their potential therapeutic or prognostic impact remains to be addressed in more detail [28-33]. To the best of our knowledge, some fusions identified in this study have not been described in the literature yet. A more detailed follow-up on the relevance of these fusions will be necessary, as our data on orientation and on in frame fusions of the coding sequences (CDS) gives only a first perception on potential functionality. Based on this limited data, PAX5-MYO1G, PAX5-NCOA6, and possibly $P A X 5$-LINC01251 seem to be promising new fusions, whose influence on the course of the disease warrants further consideration $[34,35]$. Just recently, the clinical implication of chimeric in frame $P A X 5$ fusions has been highlighted, as well as the potentially initiating, subtype-defining character of $P A X 5$ alterations in B-ALL [33]. In this respect, particularly the fusions with $M Y O 1 G$ and NCOA6, first identified in this study, appear to leave the paired box DNA-binding domain of PAX5 operational.

In conclusion, this study demonstrated that panel-based RNA-seq, supplemented by FISH analysis, and CGH+SNP arrays are a reliable combination of methods to detect the genetic markers $B C R-A B L 1, E T V 6-R U N X 1$, hypodiploidy, $I K Z F 1^{\text {plus }}$ as well as rearrangements of KMT2A and TCF3 necessary for risk stratification in pediatric BCP-ALL. Foremost, acquisition of genome-wide copy number and panel-wide fusion data within the standard diagnostic workflow is expected to support identification of new genetic markers relevant for treatment in the future. 
Funding information Open Access funding provided by Projekt DEAL. This work was supported by funding from the Deutsche Forschungsgemeinschaft (DFG, German Research Foundation) for the Cluster of Excellence REBIRTH (From Regenerative Biology to Reconstructive Therapy, EXC62) and by funding from the "HochschulinterneLeistungsförderung" (HiLF) of Hannover Medical School. AKB's work was financially supported by the DFG in the framework of the projects BE 6555/1-1 und BE 6555/2-1. GCa was financially supported by the Italian Association for Cancer Research (AIRC). GCa and GF were financially supported by the Comitato Maria Letizia Verga (CMLV).

\section{Compliance with ethical standards}

Conflict of interest The authors declare that they have no conflict of interest

Research involving human participants and/or animals For this type of study, formal consent is not required.

Informed consent Informed consent was obtained from all individual participants included in the study.

Open Access This article is licensed under a Creative Commons Attribution 4.0 International License, which permits use, sharing, adaptation, distribution and reproduction in any medium or format, as long as you give appropriate credit to the original author(s) and the source, provide a link to the Creative Commons licence, and indicate if changes were made. The images or other third party material in this article are included in the article's Creative Commons licence, unless indicated otherwise in a credit line to the material. If material is not included in the article's Creative Commons licence and your intended use is not permitted by statutory regulation or exceeds the permitted use, you will need to obtain permission directly from the copyright holder. To view a copy of this licence, visit http://creativecommons.org/licenses/by/4.0/.

\section{References}

1. Pui CH, Yang JJ, Bhakta N, Rodriguez-Galindo C (2018) Global efforts toward the cure of childhood acute lymphoblastic leukaemia. Lancet Child Adolesc Health 2(6):440-454. https://doi.org/10. 1016/S2352-4642(18)30066-X

2. Estey EH, Faderl SH, Kantarjian H (2008) Hematologic malignancies: acute leukemias. https://doi.org/10.1007/978-3-540-72304-2

3. Hunger SP, Mullighan CG (2015) Acute lymphoblastic leukemia in children. N Engl J Med 373(16):1541-1552. https://doi.org/10. 1056/NEJMra1400972

4. Pui CH, Yang JJ, Hunger SP, Pieters R, Schrappe M, Biondi A, Vora A, Baruchel A, Silverman LB, Schmiegelow K, Escherich G, Horibe K, Benoit YC, Izraeli S, Yeoh AE, Liang DC, Downing JR, Evans WE, Relling MV, Mullighan CG (2015) Childhood acute lymphoblastic leukemia: progress through collaboration. J Clin Oncol 33(27):29382948. https://doi.org/10.1200/JCO.2014.59.1636

5. Biondi A, Gandemer V, De Lorenzo P, Cario G, Campbell M, Castor A, Pieters R, Baruchel A, Vora A, Leoni V, Stary J, Escherich G, Li CK, Cazzaniga G, Cave H, Bradtke J, Conter V, Saha V, Schrappe M, Grazia Valsecchi M (2018) Imatinib treatment of paediatric Philadelphia chromosome-positive acute lymphoblastic leukaemia (EsPhALL2010): a prospective, intergroup, open-label, single-arm clinical trial. Lancet Haematol 5(12):e641-e652. https://doi.org/10.1016/S2352-3026(18)30173-X

6. van Dongen JJ, van der Velden VH, Bruggemann M, Orfao A (2015) Minimal residual disease diagnostics in acute lymphoblastic leukemia: need for sensitive, fast, and standardized technologies. Blood 125(26): 3996-4009. https://doi.org/10.1182/blood-2015-03-580027

7. Lilljebjorn $\mathrm{H}$, Henningsson R, Hyrenius-Wittsten A, Olsson L, Orsmark-Pietras C, von Palffy S, Askmyr M, Rissler M, Schrappe M, Cario G, Castor A, Pronk CJ, Behrendtz M, Mitelman F, Johansson B, Paulsson K, Andersson AK, Fontes M, Fioretos T (2016) Identification of ETV6-RUNX1-like and DUX4-rearranged subtypes in paediatric B-cell precursor acute lymphoblastic leukaemia. Nat Commun 7:11790. https://doi.org/10.1038/ncomms11790

8. Stanulla M, Dagdan E, Zaliova M, Moricke A, Palmi C, Cazzaniga G, Eckert C, Te Kronnie G, Bourquin JP, Bornhauser B, Koehler R, Bartram CR, Ludwig WD, Bleckmann K, Groeneveld-Krentz S, Schewe D, Junk SV, Hinze L, Klein N, Kratz CP, Biondi A, Borkhardt A, Kulozik A, Muckenthaler MU, Basso G, Valsecchi MG, Izraeli S, Petersen BS, Franke A, Dorge P, Steinemann D, Haas OA, Panzer-Grumayer R, Cave H, Houlston RS, Cario G, Schrappe M, Zimmermann M, Consortium T, International BFMSG (2018) IKZF1(plus) defines a new minimal residual disease-dependent very-poor prognostic profile in pediatric B-cell precursor acute lymphoblastic leukemia. J Clin Oncol 36(12): 1240-1249. https://doi.org/10.1200/JCO.2017.74.3617

9. Kachroo P, Szymczak S, Heinsen FA, Forster M, Bethune J, Hemmrich-Stanisak G, Baker L, Schrappe M, Stanulla M, Franke A (2018) NGS-based methylation profiling differentiates TCF3-HLF and TCF3-PBX1 positive B-cell acute lymphoblastic leukemia. Epigenomics 10(2):133-147. https://doi.org/10.2217/epi-2017-0080

10. Schlegelberger B, Metzke S, Harder S, Zühlke-Jenisch R, Zhang Y, Siebert R (1999) Classical and molecular cytogenetics of tumor cells. In: Wegner R-D (ed) Diagnostic cytogenetics. Springer Berlin Heidelberg, Berlin, pp 151-185. https://doi.org/10.1007/ 978-3-642-59918-7 9

11. van Dongen JJ, Macintyre EA, Gabert JA, Delabesse E, Rossi V, Saglio G, Gottardi E, Rambaldi A, Dotti G, Griesinger F, Parreira A, Gameiro P, Diaz MG, Malec M, Langerak AW, San Miguel JF, Biondi A (1999) Standardized RT-PCR analysis of fusion gene transcripts from chromosome aberrations in acute leukemia for detection of minimal residual disease. Report of the BIOMED-1 concerted action: investigation of minimal residual disease in acute leukemia. Leukemia 13(12):1901-1928

12. Cross NC, Melo JV, Feng L, Goldman JM (1994) An optimized multiplex polymerase chain reaction (PCR) for detection of BCRABL fusion mRNAs in haematological disorders. Leukemia 8(1): 186-189

13. Kim D, Pertea G, Trapnell C, Pimentel H, Kelley R, Salzberg SL (2013) TopHat2: accurate alignment of transcriptomes in the presence of insertions, deletions and gene fusions. Genome Biol 14(4): R36. https://doi.org/10.1186/gb-2013-14-4-r36

14. Kim D, Salzberg SL (2011) TopHat-fusion: an algorithm for discovery of novel fusion transcripts. Genome Biol 12(8):R72. https:// doi.org/10.1186/gb-2011-12-8-r72

15. Dobin A, Davis CA, Schlesinger F, Drenkow J, Zaleski C, Jha S, Batut P, Chaisson M, Gingeras TR (2013) STAR: ultrafast universal RNA-seq aligner. Bioinformatics 29(1):15-21. https://doi.org/10. 1093/bioinformatics/bts635

16. Chen X, Schulz-Trieglaff O, Shaw R, Barnes B, Schlesinger F, Kallberg M, Cox AJ, Kruglyak S, Saunders CT (2016) Manta: rapid detection of structural variants and indels for germline and cancer sequencing applications. Bioinformatics 32(8):1220-1222. https:// doi.org/10.1093/bioinformatics/btv710

17. Moricke A, Reiter A, Zimmermann M, Gadner H, Stanulla M, Dordelmann M, Loning L, Beier R, Ludwig WD, Ratei R, Harbott J, Boos J, Mann G, Niggli F, Feldges A, Henze G, Welte K, Beck JD, Klingebiel T, Niemeyer C, Zintl F, Bode U, Urban C, Wehinger H, Niethammer D, Riehm H, Schrappe M, GermanAustrian-Swiss ALLBFMSG (2008) Risk-adjusted therapy of acute lymphoblastic leukemia can decrease treatment burden and 
improve survival: treatment results of 2169 unselected pediatric and adolescent patients enrolled in the trial ALL-BFM 95. Blood 111(9):4477-4489. https://doi.org/10.1182/blood-2007-09-112920

18. Conter V, Bartram CR, Valsecchi MG, Schrauder A, PanzerGrumayer R, Moricke A, Arico M, Zimmermann M, Mann G, De Rossi G, Stanulla M, Locatelli F, Basso G, Niggli F, Barisone E, Henze G, Ludwig WD, Haas OA, Cazzaniga G, Koehler R, Silvestri D, Bradtke J, Parasole R, Beier R, van Dongen JJ, Biondi A, Schrappe M (2010) Molecular response to treatment redefines all prognostic factors in children and adolescents with B-cell precursor acute lymphoblastic leukemia: results in 3184 patients of the AIEOP-BFM ALL 2000 study. Blood 115(16):32063214. https://doi.org/10.1182/blood-2009-10-248146

19. Roberts KG, Li Y, Payne-Turner D, Harvey RC, Yang YL, Pei D, McCastlain K, Ding L, Lu C, Song G, Ma J, Becksfort J, Rusch M, Chen SC, Easton J, Cheng J, Boggs K, Santiago-Morales N, Iacobucci I, Fulton RS, Wen J, Valentine M, Cheng C, Paugh SW, Devidas M, Chen IM, Reshmi S, Smith A, Hedlund E, Gupta P, Nagahawatte P, Wu G, Chen X, Yergeau D, Vadodaria B, Mulder H, Winick NJ, Larsen EC, Carroll WL, Heerema NA, Carroll AJ, Grayson G, Tasian SK, Moore AS, Keller F, Frei-Jones M, Whitlock JA, Raetz EA, White DL, Hughes TP, Guidry Auvil JM, Smith MA, Marcucci G, Bloomfield CD, Mrozek K, Kohlschmidt J, Stock W, Kornblau SM, Konopleva M, Paietta E, Pui CH, Jeha S, Relling MV, Evans WE, Gerhard DS, Gastier-Foster JM, Mardis E, Wilson RK, Loh ML, Downing JR, Hunger SP, Willman CL, Zhang J, Mullighan CG (2014) Targetable kinase-activating lesions in Ph-like acute lymphoblastic leukemia. N Engl J Med 371(11):1005-1015. https://doi.org/ 10.1056/NEJMoa1403088

20. Boer JM, Steeghs EM, Marchante JR, Boeree A, Beaudoin JJ, Beverloo HB, Kuiper RP, Escherich G, van der Velden VH, van der Schoot CE, de Groot-Kruseman HA, Pieters R, den Boer ML (2017) Tyrosine kinase fusion genes in pediatric BCR-ABL1-like acute lymphoblastic leukemia. Oncotarget 8(3):4618-4628. https:// doi.org/10.18632/oncotarget.13492

21. Boer JM, den Boer ML (2017) BCR-ABL1-like acute lymphoblastic leukaemia: from bench to bedside. Eur J Cancer 82:203-218. https://doi.org/10.1016/j.ejca.2017.06.012

22. Mrozek K, Harper DP, Aplan PD (2009) Cytogenetics and molecular genetics of acute lymphoblastic leukemia. Hematol Oncol Clin North Am 23(5):991-1010, v. https://doi.org/10.1016/j.hoc.2009.07.001

23. Roberts KG, Janke LJ, Zhao Y, Seth A, Ma J, Finkelstein D, Smith S, Ebata K, Tuch BB, Hunger SP, Mullighan CG (2018) ETV6NTRK3 induces aggressive acute lymphoblastic leukemia highly sensitive to selective TRK inhibition. Blood 132(8):861-865. https://doi.org/10.1182/blood-2018-05-849554

24. Steeghs EMP, Jerchel IS, de Goffau-Nobel W, Hoogkamer AQ, Boer JM, Boeree A, van de Ven C, Koudijs MJ, Besselink NJM, de Groot-Kruseman HA, Zwaan CM, Horstmann MA, Pieters R, den Boer ML (2017) JAK2 aberrations in childhood B-cell precursor acute lymphoblastic leukemia. Oncotarget 8(52):89923-89938. https://doi.org/10.18632/oncotarget.21027

25. Russell LJ, Capasso M, Vater I, Akasaka T, Bernard OA, Calasanz MJ, Chandrasekaran T, Chapiro E, Gesk S, Griffiths M, Guttery DS, Haferlach C, Harder L, Heidenreich O, Irving J, Kearney L, Nguyen-Khac F, Machado L, Minto L, Majid A, Moorman AV, Morrison H, Rand V, Strefford JC, Schwab C, Tonnies H, Dyer MJ, Siebert R, Harrison CJ (2009) Deregulated expression of cytokine receptor gene, CRLF2, is involved in lymphoid transformation in B-cell precursor acute lymphoblastic leukemia. Blood 114(13): 2688-2698. https://doi.org/10.1182/blood-2009-03-208397

26. Iacobucci I, Mullighan CG (2017) Genetic basis of acute lymphoblastic leukemia. J Clin Oncol 35(9):975-983. https://doi.org/10. 1200/JCO.2016.70.7836

27. Gu Z, Churchman M, Roberts K, Li Y, Liu Y, Harvey RC, McCastlain K, Reshmi SC, Payne-Turner D, Iacobucci I, Shao Y, Chen IM,
Valentine M, Pei D, Mungall KL, Mungall AJ, Ma Y, Moore R, Marra M, Stonerock E, Gastier-Foster JM, Devidas M, Dai Y, Wood B, Borowitz M, Larsen EE, Maloney K, Mattano LA Jr, Angiolillo A, Salzer WL, Burke MJ, Gianni F, Spinelli O, Radich JP, Minden MD, Moorman AV, Patel B, Fielding AK, Rowe JM, Luger SM, Bhatia R, Aldoss I, Forman SJ, Kohlschmidt J, Mrozek K, Marcucci G, Bloomfield CD, Stock W, Kornblau S, Kantarjian HM, Konopleva M, Paietta E, Willman CL, Loh ML, Hunger SP, Mullighan CG (2016) Genomic analyses identify recurrent MEF2D fusions in acute lymphoblastic leukaemia. Nat Commun 7:13331. https://doi.org/10. 1038/ncomms13331

28. Reshmi SC, Harvey RC, Roberts KG, Stonerock E, Smith A, Jenkins H, Chen IM, Valentine M, Liu Y, Li Y, Shao Y, Easton J, Payne-Turner D, Gu Z, Tran TH, Nguyen JV, Devidas M, Dai Y, Heerema NA, Carroll AJ 3rd, Raetz EA, Borowitz MJ, Wood BL, Angiolillo AL, Burke MJ, Salzer WL, PA Z-MK, Rabin KR, Carroll WL, Zhang J, Loh ML, Mullighan CG, Willman CL, Gastier-Foster JM, Hunger SP (2017) Targetable kinase gene fusions in high-risk B-ALL: a study from the Children's Oncology Group. Blood 129(25):3352-3361. https://doi.org/10.1182/blood-2016-12-758979

29. Nebral K, Denk D, Attarbaschi A, Konig M, Mann G, Haas OA, Strehl S (2009) Incidence and diversity of PAX5 fusion genes in childhood acute lymphoblastic leukemia. Leukemia 23(1):134143. https://doi.org/10.1038/leu.2008.306

30. Gocho $\mathrm{Y}$, Kiyokawa N, Ichikawa H, Nakabayashi K, Osumi T, Ishibashi T, Ueno H, Terada K, Oboki K, Sakamoto H, Shioda Y, Imai M, Noguchi Y, Arakawa Y, Kojima Y, Toyama D, Hata K, Yoshida T, Matsumoto K, Kato M, Fukushima T, Koh K, Manabe A, Ohara A, Tokyo Children's Cancer Study G (2015) A novel recurrent EP300ZNF384 gene fusion in B-cell precursor acute lymphoblastic leukemia. Leukemia 29(12):2445-2448. https://doi.org/10.1038/leu.2015.111

31. McClure BJ, Heatley SL, Kok CH, Sadras T, An J, Hughes TP, Lock RB, Yeung D, Sutton R, White DL (2018) Pre-B acute lymphoblastic leukaemia recurrent fusion, EP300-ZNF384, is associated with a distinct gene expression. Br J Cancer 118(7):1000-1004. https://doi.org/10.1038/s41416-018-0022-0

32. Cazzaniga G, Daniotti M, Tosi S, Giudici G, Aloisi A, Pogliani E, Kearney L, Biondi A (2001) The paired box domain gene PAX5 is fused to ETV6/TEL in an acute lymphoblastic leukemia case. Cancer Res 61(12):4666-4670

33. Gu Z, Churchman ML, Roberts KG, Moore I, Zhou X, Nakitandwe J, Hagiwara K, Pelletier S, Gingras S, Berns H, Payne-Turner D, Hill A, Iacobucci I, Shi L, Pounds S, Cheng C, Pei D, Qu C, Newman S, Devidas M, Dai Y, Reshmi SC, Gastier-Foster J, Raetz EA, Borowitz MJ, Wood BL, Carroll WL, Zweidler-McKay PA, Rabin KR, Mattano LA, Maloney KW, Rambaldi A, Spinelli O, Radich JP, Minden MD, Rowe JM, Luger S, Litzow MR, Tallman MS, Racevskis J, Zhang Y, Bhatia R, Kohlschmidt J, Mrozek K, Bloomfield CD, Stock W, Kornblau S, Kantarjian HM, Konopleva M, Evans WE, Jeha S, Pui CH, Yang J, Paietta E, Downing JR, Relling MV, Zhang J, Loh ML, Hunger SP, Mullighan CG (2019) PAX5-driven subtypes of Bprogenitor acute lymphoblastic leukemia. Nat Genet 51(2):296-307. https://doi.org/10.1038/s41588-018-0315-5

34. Lopez-Ortega O, Ovalle-Garcia E, Ortega-Blake I, Antillon A, Chavez-Munguia B, Patino-Lopez G, Fragoso-Soriano R, SantosArgumedo L (2016) Myolg is an active player in maintaining cell stiffness in B-lymphocytes. Cytoskeleton (Hoboken) 73(5):258 268. https://doi.org/10.1002/cm.21299

35. Mahajan MA, Samuels HH (2008) Nuclear receptor coactivator/ coregulator $\mathrm{NCoA6}(\mathrm{NRC})$ is a pleiotropic coregulator involved in transcription, cell survival, growth and development. Nucl Recept Signal 6:e002. https://doi.org/10.1621/nrs.06002

Publisher's note Springer Nature remains neutral with regard to jurisdictional claims in published maps and institutional affiliations. 